\title{
Explicit and implicit affiliation motives predict verbal and nonverbal social behavior in sports competition
}

\author{
Mirko Wegner ${ }^{\mathrm{a},{ }^{*}}$, Vincent Bohnacker ${ }^{\mathrm{b}}$, Gordon Mempel ${ }^{\mathrm{c}}$, Thomas Teubel ${ }^{\mathrm{d}}$, \\ Julia Schüler ${ }^{a}$ \\ a University of Bern, Switzerland \\ ${ }^{\mathrm{b}}$ Freie Universitat Berlin, Germany \\ ${ }^{\mathrm{c}}$ Humboldt-Universitat zu Berlin, Germany \\ d Business School Berlin Potsdam, Germany
}

Keywords:

Affiliation

Motivation

Competition

Social interaction

Racquet sports

\begin{abstract}
A B S T R A C T
Objectives: The present study investigated the predictive value of the explicit and implicit affiliation motive for social behavior in sport competitions. From an information processing perspective, an explicit motive is linked to verbal cues and respondent behavior. The implicit motive in turn is linked to nonverbal stimuli and operant behavior (McClelland, Koestner, \& Weinberger, 1989; Schultheiss, 2008). Both respondent affiliative behavior (e.g., verbal interactions with teammates) and operant nonverbal social behavior (e.g., pleasant to opponents) can be observed in racquet sports team competitions.

Design \& Methods: Fifty two male racquet sportsmen completed the Personality Research Form (explicit affiliation motive) and the Operant Motive Test (implicit affiliation motive). Motive measures were used to predict social behavior during competitions using multiple regression analyses. To this aim real competitive matches were videotaped and analyzed.

Results: Results show that the explicit affiliation motive is associated with time spent in verbal team contact. The implicit affiliation motive, by contrast, is linked to pleasant nonverbal behavior shown to ward opponents.

Conclusions: Findings suggest that implicit and explicit affiliation motives predict different kinds of social behavior in sports competition respectively. Indirect motive measures may be of additional predictive value for different behavior in real sports settings.
\end{abstract}

Playing singles competitions in racquet sports is a very lonely endeavor for the players involved when it comes to social inter action during matches, personal responsibility for errors, or the need to travel alone. In contrast to singles competitions, there are team competitions in all three sports of tennis, badminton, and table tennis that leave much more space for social behavior. These team competitions are either national league, collegiate sport, or international competitions such as world championships, Olympic Games, or the Davis Cup in tennis. In tennis, for example, even the rules for social interaction in team competitions differ from the singles competitions. In tennis team competitions, social exchange with teammates or coaches is allowed during breaks. Athletes can talk to their teammates between rallies as well. In

\footnotetext{
* Corresponding author. University of Bern, Institute of Sport Science, Fabrikstrasse 8, 3012 Bern, Switzerland. Tel.: +4131 6315659.

E-mail address: mirko.wegner@ispw.unibe.ch (M. Wegner).
}

badminton, for example, a teammate is even allowed to sit right behind the player during the whole match. In addition to the interaction with opponents or referees commonly found in singles competitions, in team competitions the athlete has the opportu nity to explicitly interact with his teammate or coach throughout the match.

In the present study, we were interested in whether athletes who usually compete alone and rely on themselves - without the help of any other teammate or coach - actually use this opportunity for social interaction during a racquet sports game. We investigated whether the social behavior shown in a match could be related to the strength of their implicit vs. explicit affiliation motives. This is particularly interesting because we observed highly competitive matches in which social interaction and affiliation should have been of little interest to the players involved. As the data in the present study illustrate, players vary in the degree to which they make use of opportunities for social interaction. 


\section{The explicit vs. implicit affiliation motive}

The affiliation motive is defined as a person's willingness to establish, maintain, or restore friendly and positive relations with others (French \& Chadwick, 1956; Schultheiss \& Pang, 2007). Peo ple with a high affiliation motive enjoy the presence of others and show positive social behavior more frequently (Jemmott, 1987; McClelland, 1985b; Sokolowski, 2008). Friendly relationships with others can be achieved through verbal interaction such as talking, writing letters or calling someone on the phone (Lansing \& Heyns, 1959; McAdams \& Constantian, 1983). Affiliative behavior can also be observed in nonverbal behavior like eye contact with others (Exline, 1963), evading conflicts in a group setting, or even evading games involving arguing with strangers (Exline, 1962; McClelland, 1975, 1985b). Exline (1962), for example, could show that partici pants with a high implicit affiliation motive avoided making de cisions when they were put in a group with two strangers working on a task requiring team coordination and effort. One of the au thor's explanations was that subjects high in the affiliation motive avoid disagreements and possible antagonisms with unknown persons. This finding is also relevant to racquet sports in which the interaction with alien opponents is common.

Verbal and nonverbal behavior have been associated with different motivational systems respectively and reflect how explicit or implicit motives are expressed in human behavior (McClelland, Koestner, \& Weinberger, 1989; Schultheiss, 2008). According to McClelland et al. (1989), explicit motives have a cognitive base, are triggered by verbal stimuli and social expectations, and are associ ated with respondent, controlled behavior such as conscious de cisions, goals, attitudes, or wishes (Schultheiss, 2008). For example, if individuals are asked to make a personal judgment in a ques tionnaire about how much they like being with others or doing ac tivities with others, the explicit motive is assumed to be of predictive value (McClelland, 1985a). The questionnaire response is assumed to reflect a deliberate and conscious wish for friendly relationships with others (Wong \& Csikszentmihalyi, 1991). With an experience sampling technique, Wong and Csikszentmihalyi (1991) found that participants high in the explicit affiliation motive significantly more often wish to be with friends as expressed in random samples taken throughout the day when compared to students with a low affili ation motive. Other researchers found that sport students' self attribution of personal cooperativeness and sociability are linked to measures of the explicit affiliation motive (Elbe, Krippl, Melzer, \& Teubel, 2013). Moreover, people with a high explicit affiliation motive display a more positive attitude toward giving and receiving in a team, and show greater concern for their teammates (Brewer \& Klein, 2006). The explicit motive is thus predominantly reflected in how much a person values social interaction.

Implicit motives, in contrast, are affectively based goal concerns that energize, orient, and select behavior (McClelland, 1985b, p. 590). They are activated by nonverbal cues, action innate in centives, and manifest themselves in operant behavior, spontane ously uttered and repeatedly generated, over which individuals to a large degree have no conscious control (McClelland, 1980; Schultheiss \& Pang, 2007). Individuals with a high implicit affilia tion motive have accordingly more spontaneous social contact and interpersonal thoughts over the course of the day and experience more positive affect in interpersonal situations (McAdams \& Constantian, 1983; McClelland, 1985a). They show more dyadic friendship episodes and more self disclosure (McAdams, Healey, \& Krause, 1984). They are sympathetic and accommodating toward others (Koestner \& McClelland, 1992; Sorrentino \& Field, 1986), show lower cortisol responses to social stressors (Wegner, Schüler, \& Budde, 2014), try to please their affiliative counterparts (McClelland, 1975), place a high value on living in a peaceful environment (Rokeach, 1973), and evade interpersonal conflicts with strangers (Exline, 1962).

\section{Measuring explicit and implicit motives}

The difference between the two motivational systems is especially important when it comes to motive assessment. Explicit motives are measured directly, by responding to self statements in questionnaires (Jackson, 1999; Mehrabian, 1970). Implicit motives, in turn, can be determined indirectly by exposing participants to picture stimuli (Schultheiss \& Pang, 2007). In picture story exercises, for example, individuals have to write a story (PSE; Schultheiss \& Pang, 2007), or reply to guiding questions in a written form (OMT; Kuhl \& Scheffer, 1999). Interestingly, it could be shown that measures of explicit and implicit motives are only weakly associated (deCharms, Morrison, Reitman, \& McClelland, 1955; Spangler, 1992). Low, non significant correlations between explicit and implicit motive measures are usu ally found (e.g., $r$ s < .16, Schüler, Job, Frohlich, \& Brandstatter, 2008; $r \quad$.09, Spangler, 1992; $r \quad .02$, Wegner \& Teubel, in press). The conceptual difference between explicit and implicit motives un derlines the importance of stating clearly which motivational process is targeted, what kind of behavior is supposed to be predicted, and what instrument should be used. It is expected that explicit motives measured with questionnaires predict respondent behavior such as attitudes, opinions, self attributes of personality (Spangler, 1992), and deliberate decision behavior (Wegner \& Teubel, in press). By contrast, implicit motive measures are better at predicting operant behavior including long term, self initiated, and spontaneously shown behavior like occupational success, participation in organizations, or affiliative behavior occurring in natural settings (McClelland et al., 1989; Spangler, 1992), such as described in the present research. The predictive power of implicit motives for operant behavior is especially high if the behavior includes activity incentives.

\section{The affiliation motive in a sport context}

The affiliation motive has so far rarely been the matter of investi gation in competitive sport settings. Yet its relevance has been illus trated for establishing and maintaining sport participation, as well as for performances in groups compared to individual settings. In several studies affiliation and social interaction (measured using self reports) have been shown to be a great motivator for sport participation (e.g., Gill \& Williams, 1996; Sudeck, Lehnert, \& Conzelmann, 2011). For non competitive cyclists, for example, the social aspect is the central reason for getting involved in and maintaining cycling (Brown, O'Connor, \& Barkatsas, 2009). It could also be shown that higher levels of the explicit affiliation motive could be found in team sports compared to individual sports (Elbe et al., 2013). In a field experiment with competitive intercollegiate swimmers, Sorrentino and Sheppard (1978) found faster swimming speeds in a group competition compared to an individual competition for athletes with higher affil iation motivation. In a golf putt experiment, students with an ad vantageous combination of the explicit affiliation motives (a low avoi dance component) scored better when they performed in a team com pared to when they performed only for themselves (Teubel, 2012). However, these experiments used measures of explicit and implicit affiliation motives indiscriminately or even combined explicit and implicit motive measures. It can be assumed that the decision for a measure of explicit or implicit affiliation motives was primarily based on the kind of dependent affiliation variable employed, as well as considerations regarding test economics. Questionnaires (explicit motives), for example, require less time for participants to complete as well as for evaluators to analyze when compared to implicit motive measures. 


\section{Objectives for the present study}

The aim of the present study was to investigate whether the affiliation motive is associated with various social behaviors in competitive sports settings. Particularly, our goal was to differen tiate between associations of explicit and implicit motives with different variables of social behavior. McClelland et al. (1989) had previously related explicit motives with respondent and verbal behavior, while implicit motives could be linked to spontaneously uttered, operant behavior. Consequently, we assumed that in a field setting the explicit affiliation motive is associated with verbal social interactions, especially in restricted situations, in which social interaction is expected from teammates. The implicit affiliation motive, in contrast, was expected to be linked to nonverbal social behavior in more open situations with greater freedom of action. In team competitions in racquet sports, athletes frequently talk to teammates and coaches to receive encouragement or demonstrate their team affiliation. This kind of verbal social interaction with teammates is socially valued and expected. We concluded that verbal interactions with teammates are likely to be correlated with the explicit affiliation motive. We also assumed that this verbal format is more closely associated with the explicit motivational system than with the implicit; meaning that athletes conform to what is expected from them regarding social interaction, rather than how they would intuitively interact with others.

By contrast, we were also interested in nonverbal social behavior shown by athletes toward their opponents. We assumed that this behavior would rather represent intuitive affiliation behavior because friendly interaction with the opponent is not expected in highly competitive sports. In elite table tennis, for example, quali tative analyses revealed that not only sport related actions but also expressions of emotions are meant to hinder or bother opponents in order to put pressure on them, gain an advantage, and finally win a match (Sève, Ria, Poizat, Saury, \& Durand, 2007; Sève, Saury, Theureau, \& Durand, 2002). In fact, practices such as bad mouthing and provoking opponents are accepted by many ath letes (Dixon, 2007; Shields, Bredemeier, LaVoi, \& Power, 2005). Our assumption was that if athletes' behavior in elite sport competition is usually meant to bother the opponent, pleasant behavior toward the opponent should be unintentional. Hence we were interested in the nonverbal behavior athletes showed toward their opponents. Corresponding nonverbal behaviors in a racquet sport competition can be observed at side change, when returning to the court, or in evasion of discussion with opponents. The implicit affiliation motive has been previously associated with valuing living in a peaceful environment and evading interpersonal conflicts (Exline, 1962; Rokeach, 1973). Exline (1962) found that persons high in the affili ation motive avoided decisions that affected strangers involved in the group task. Accordingly, in the present study, we expected athletes with high implicit affiliation motives to return earlier to the court once their opponent displayed readiness to compete again, and a higher degree of evading of discussion with their opponents.

Hypotheses. We assumed that the explicit, but not the implicit, affiliation motive predicts the amount of verbal interaction with teammates. In contrast, we hypothesized that the implicit, but not the explicit, affiliation motive is a predictor for the nonverbal behavior shown toward the competitive opponent.

\section{Material and methods}

\section{Participants and procedure}

Fifty two male athletes with a mean age of 28.2 years (SD $\quad 6.9$, ranging from 17 to 49 ) participated in the study. All participants were active professionals in the German major leagues (Bunde sliga) of tennis ( $n$ 17), table tennis ( $n$ 22), and badminton ( $n$ 13). Players originated from twelve different nations (pre dominantly European) among them Argentina, Belgium, Canada, Chile, China, England, Germany, Hungary, Italy, the Netherlands, Romania, and Sweden. All were invited to participate prior to the start of the season via mailing lists of the respective sports federations.

The present study was approved by the local ethics board and conducted in accordance with the ethical principles of the Amer ican Psychological Association (APA). Athletes signed a form of informed consent to participate in the present study before work ing on an online version of a survey on explicit and implicit motives. After tests had been completed, one major league match of each player was recorded and analyzed. Individual matches were recorded using a conventional camera with a wide angle lens that allowed for keeping the whole court in view. The games of 52 athletes were videotaped and analyzed by three raters regarding verbal and nonverbal social behavior shown toward teammates and opponents.

\section{Measures}

\section{Explicit motive measure}

In order to assess the explicit affiliation motive, the affiliation scale of the Personality Research Form was administered (PRF; Jackson, 1999). The PRF can also be used to assess other motives like the achievement or power motive. The scale consists of 16 self statements that have to be answered with "right" or "wrong". This scale is intended as a self assessment of how much a person enjoys being together with others, accepts people easily, or makes an effort to enter a friendship and maintain connections with other people (Stumpf, Angleitner, Wieck, Jackson, \& Beloch Till, 1985, p. 44). An exemplary item for the affiliation scale is, "I go out of my way to meet people". The explicit affiliation motive index was computed by cumulating the items agreed with (Cronbach's $\alpha \quad$.69). The mean explicit affiliation motive score was $M \quad 10.8$ (SD 3.1) ranging from 4 to 16 . The self rating with the affiliation scale of the PRF, for example, has previously been shown to be related to the frequency of the wish to spend time with friends (Wong \& Csikszentmihalyi, 1991), or to peer ratings of affiliation (Jackson, 1999, p. 60).

\section{Implicit motive measure}

The Operant Motive Test (OMT; Kuhl \& Scheffer, 1999) is used to assess the strength of different implicit motives like affiliation, achievement, and power. In the present study, it was administered to assess the implicit affiliation motive. The test consists of 15 pictures showing sketches of people. In each picture a protagonist had to be chosen first, and subsequently four questions had to be answered in the form of short and spontaneous notes. The ques tions were: (1) What is important for the person in this situation and what is the person doing?, (2) How does the person feel?, (3) Why does the person feel this way?, (4) How does the story end? According to the five criteria of the OMT manual, the affiliation motive was coded whenever the responses indicated (A) friendly intuitive ex change between people, (B) having fun with others, (C) solving problems in relationships with others, (D) seeking security in the relationship with others, or (E) indicated feelings of being alone. Whole pictures were either coded or not coded for the affiliation motive. For the present study, the overall affiliation motive score was computed out of a total of all 15 pictures presented. Two experienced coders conducted the scoring of the OMT pictures and reached satisfactory interrater reliability of .81 and an intrarater reliability of .84 . The average implicit affiliation motive score was 
M 2.3 (SD 1.3), ranging from 0 to 5 . Sufficient internal consis tency and retest reliability for the OMT has previously been re ported (Scheffer, Kuhl, \& Eichstaedt, 2003). The implicit affiliation scale of the OMT, for example, was shown to be positively linked to friendly customer orientation (Scheffer, Eichstaedt, Chasiotis, \& Kuhl, 2007), the age of the first close relationship (Scheffer, 2001), and right hemispheric activity (Kuhl \& Kazén, 2008).

\section{Explicit affiliation behavior}

The total time athletes spent in verbal social interaction with teammates was assessed for the whole match. The overall verbal contact with teammates was divided by the overall match time. In order to render data comparable over all three kinds of sports (tennis, table tennis, badminton), the time is given in seconds spent on social contact with the team in a ten minute playing interval.

Additionally, the percentage of total break time spent in verbal contact with teammates was calculated. Breaks were defined ac cording to the rules of each sport. These included rest periods in which a player is allowed to go to the bench or take a towel. Among those were also inter set breaks for all three sports. These breaks included side changes for tennis, timeouts for table tennis, and the set half time breaks for badminton. The three sports did not differ with regard to the relative amount of break time and break length throughout the match. All time intervals of verbal social contact were assessed by three observers ${ }^{1}$ using stopwatches, who were blind to the hypotheses (interrater reliability ICC .99).

\section{Implicit affiliation behavior}

Nonverbal social behavior was operationalized using two vari ables. The first variable was pleasant behavior at side change. It was coded as the average time in seconds it took a player to return to the court after a break, and after his opponent had already returned. ${ }^{2}$ The earlier the player returned to the court the more pleasant he was behaving toward his opponent. The time interval began when the opponent ended his break by turning away from the bench and making his first step back onto the court. The average time for pleasant behavior at side change was defined as the time gap until the observed player made his first step back onto the court and was averaged for all breaks in which the investigated player was the last to end the break. We assumed that returning late while the opponent is ready to play would be an offense to the opponent because the opponent signals his will to go on by returning to the court first.

The second variable was the average amount of time the observed athlete evaded discussion with his opponent about a ref eree's decision over the course of the match. For example, players asked each other whether a decision of a referee's "out" call was really correct, or they asked their opponents to overrule the referee. This time was summed up and divided by the total length of the game. In order to be able to compare the scores for evasion of discussion between the three kinds of sports, it is given in seconds per ten minutes of playing time. Again, time intervals for pleasant behavior at side change and evasion of discussion were determined with stopwatches by the same three observers (interrater reliability ICC .99).

\footnotetext{
${ }^{1}$ For explicit and implicit affiliation behavior raters were trained using sample scenes in two sessions including one hundred possible coding events for each measure. Coder training was projected to continue until raters reach inter-rater reliabilities of at least .85 . However, raters agreement was already .99 after only one session.

2 We performed a preliminary analysis of players' frequencies of returning late. These were equally distributed over the three different sports. However, since neither the explicit nor the implicit affiliation motive was associated with players' frequencies of returning late these results are not included in the present report.
}

\section{Results}

Multiple regression analyses were conducted to determine the differentiating predictive value of explicit and implicit affiliation motives on verbal and nonverbal social behavior in racquet sport competitions. The explicit and implicit affiliation motive measures were entered into one regression model.

During data analysis the motive scores and the verbal as well as nonverbal behavior variables were $z$ standardized within each type of sport. This was done since average match durations in minutes significantly differed between the sports of tennis (M 86.4, $S D$ 18.9), table tennis ( $M \quad 29.8, S D \quad 9.3)$, and badminton ( $M \quad 49.3, S D \quad 11.2), F \quad 97.88, p \quad .001, \eta^{2} \quad .80$. This assured that differences could be attributed to individuals rather than system atic differences due to the type of sport.

\section{Descriptive statistics}

Regarding the type of sport, individuals did not significantly differ concerning overall verbal team contact, $F \quad 2.02, p \quad .14$, verbal team contact in breaks, $F \quad 2.11, p \quad .13$, evading discussion with opponents, $F \quad 0.49, p \quad .62$, or pleasant behavior toward the opponent at side change, $F \quad 2.41, p \quad .11$. Means and standard deviations for social behavior criteria are given in Table 1.

Tennis, table tennis, and badminton players used about $10 \%$ of the total match time for verbal social contact (55 s of ten minutes playing time). Around $69 \%$ of break time was spent in verbal social contact with one's own team. On average $597 \mathrm{~s}$ per ten minutes were spent on evading discussion with the opponent. Additionally, the opposing player had to wait for approximately $12 \mathrm{~s}$ after breaks if the observed player was the latter to return to the court (pleasant at side change). These $12 \mathrm{~s}$ were the average amount of time (delta) between the opponent and the observed player. They only refer to the instances in which the observed player was the second to re turn to the court.

Table 2 shows inter correlation coefficients (Pearson, two tailed) for explicit and implicit motive measures and the variables of verbal team contact and nonverbal behavior toward the oppo nent. As expected, no significant association between explicit (PRF) and implicit affiliation motive measures (OMT) could be observed $\left(\begin{array}{lll}r & .01, p & .96\end{array}\right)$. The explicit affiliation motive was significantly associated with the overall time spent on verbal team contact throughout the match $\left(\begin{array}{lll}r & .34, p & .01\end{array}\right)$, and the percentage of verbal team contact within breaks $(r \quad .38, p \quad .01)$. However, the implicit affiliation motive was associated with nonverbal behavior toward the opponent. Both, evading of discussion with the oppo

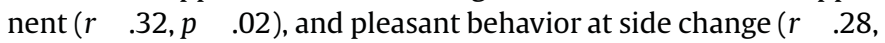
$p \quad .05)$, were linked to the implicit affiliation motive score.

Table 1

Means $(M)$ and standard deviations $(S D)$ of overall time spent in verbal contact with teammates (in seconds per $10 \mathrm{~min}$ ), percentage of time spent in verbal contact with teammates in breaks, and time spent on nonverbal behavior toward the opponent (evading of discussion, pleasant at side change).

\begin{tabular}{|c|c|c|c|c|}
\hline & $\begin{array}{l}\text { Total } \\
\left(\begin{array}{ll}N & 52\end{array}\right)\end{array}$ & $\begin{array}{l}\text { Tennis } \\
\left(\begin{array}{ll}n & 17\end{array}\right)\end{array}$ & $\begin{array}{l}\text { Table tennis } \\
\left(\begin{array}{ll}n & 22\end{array}\right)\end{array}$ & $\begin{array}{l}\text { Badminton } \\
\left(\begin{array}{ll}n & 13\end{array}\right)\end{array}$ \\
\hline & $M(S D)$ & $M(S D)$ & $M(S D)$ & $M(S D)$ \\
\hline \multicolumn{5}{|c|}{ Explicit verbal team contact } \\
\hline Overall (sec/10 min) & $55.2(22.6)$ & $49.2(27.7)$ & $60.9(18.7)$ & $47.1(20.1)$ \\
\hline In Breaks (\%) & $68.6(21.9)$ & $60.7(32.9)$ & $70.8(9.4)$ & $78.8(21.2)$ \\
\hline \multicolumn{5}{|c|}{ Implicit nonverbal behavior toward opponent } \\
\hline $\begin{array}{l}\text { Evade discussion } \\
\text { (sec/10 min) }\end{array}$ & $597.1(1.9)$ & $597.3(1.5)$ & $597.2(2.2)$ & $596.5(1.6)$ \\
\hline $\begin{array}{l}\text { Pleasant at side } \\
\text { change (sec) }\end{array}$ & $12.0(8.2)$ & $10.3(6.8)$ & $11.5(7.6)$ & $18.0(11.4)$ \\
\hline
\end{tabular}


Table 2

Inter-correlations (Pearson, two-tailed) of implicit and explicit motives and variables of observed verbal and nonverbal social behavior toward teammates and opponents.

\begin{tabular}{llllll}
\hline & 2 & 3 & 4 & 5 & 6 \\
\hline 1 Implicit affiliation motive & -.01 & .09 & .08 & $-.28^{*}$ & $.32^{*}$ \\
2 Explicit affiliation motive & & $.34^{*}$ & $.38^{* *}$ & .13 & .11 \\
3 Verbal team contact (overall) & & & $.69^{* *}$ & .27 & .22 \\
4 Verbal team contact (in breaks) & & & & .11 & .23 \\
5 Pleasant at side change (opponent, sec) & & & & & -.16 \\
6 Evade discussion (opponent) & & & & &
\end{tabular}

Note. ${ }^{*} p<.05,{ }^{* *} p<.01$.

\section{The explicit affiliation motive predicts verbal team contact}

Multiple regression analyses were performed to determine the effect the explicit affiliation motive has on verbal team contact. We expected that the implicit affiliation motive cannot account for variance in duration of verbal team contact in competition.

\section{Overall verbal team contact}

The explicit affiliation motive was a significant predictor of overall verbal team contact in racquet sport competition, $t(51) \quad 2.58, \beta \quad .34, p \quad .01$. In contrast, the implicit affiliation motive did not significantly account for variance in overall verbal team contact, $t(51) \quad 0.67, \beta \quad .09, p \quad .51$. The entire regression model significantly explained $13 \%$ of variance in overall verbal team contact, $R^{2} \quad .13, F(2,49) \quad 3.53, p \quad .04$. An overview of the results of the regression analyses conducted is given in Table 3 .

\section{Verbal team contact in breaks}

The explicit affiliation motive was also a significant predictor of the percentage of time spent on verbal team contact in breaks, $t(51) \quad 2.91, \beta \quad .38, p \quad .01$. Again, implicit affiliation did not ac count for variance in verbal team contact during breaks, $t(51) \quad 0.62, \beta \quad .08, p \quad .54$. Overall, the regression model accounted for $15 \%$ of the variance of verbal team contact in breaks, $R^{2} \quad .15, F(2,49) \quad 4.40, p \quad .02$.

\section{The implicit affiliation motive predicts nonverbal social behavior toward the opponent}

In order to assess the predictive value of the explicit and implicit affiliation motives on nonverbal social behavior toward the oppo nent, multiple regression analyses were conducted as well.

Table 3

Overview of the regression analyses with explicit and implicit affiliation motives as predictors, verbal team contact and nonverbal behavior toward the opponent as criteria.

\begin{tabular}{|c|c|c|c|c|}
\hline & \multicolumn{2}{|c|}{ Verbal team contact } & \multicolumn{2}{|c|}{ Nonverbal behavior to opponent } \\
\hline & Overall & In breaks & $\begin{array}{l}\text { Pleasant at } \\
\text { side change (sec) }\end{array}$ & $\begin{array}{l}\text { Evade discussion } \\
\text { w/Opponent }\end{array}$ \\
\hline & $B(S E)$ & $B(S E)$ & $B(S E)$ & $B(S E)$ \\
\hline \multicolumn{5}{|l|}{ Constant } \\
\hline$B(S E)$ & $0.00(0.13)$ & $0.00(0.13)$ & $0.00(0.14)$ & $0.00(0.13)$ \\
\hline \multicolumn{5}{|c|}{ Explicit Affiliation } \\
\hline$B(S E)$ & $0.32(0.13)$ & $0.36(0.12)$ & $0.12(0.13)$ & $-0.10(0.13)$ \\
\hline$\beta$ & $.34^{*}$ & $.38^{* *}$ & .02 & .11 \\
\hline \multicolumn{5}{|c|}{ Implicit Affiliation } \\
\hline$B(S E)$ & $0.08(0.13)$ & $0.08(0.12)$ & $-0.26(0.13)$ & $-0.30(0.13)$ \\
\hline$\beta$ & .09 & .08 & $-.28^{*}$ & $.32^{*}$ \\
\hline$R^{2}$ & $.13^{*}$ & $.15^{*}$ & $.09 \dagger$ & $.11^{*}$ \\
\hline
\end{tabular}

Note. $\dagger p<.10,{ }^{*} p<.05,{ }^{* *} p<.01$.
Pleasant behavior at side change

The implicit affiliation motive measure significantly predicted pleasant behavior toward the opponent at side change, $t(51) \quad 2.00$, $p \quad .05$. The higher an athlete's implicit affiliation motive was, the earlier he would return to the court after a break as a favor to his opponent, $\beta \quad$.28. The explicit affiliation motive, in contrast, did not account for variance in pleasant behavior at side change, $t(51) \quad 0.89, \beta \quad .02, p \quad$.38. For pleasant behavior toward the opponent at side change the regression model was only marginally significant, $R^{2} \quad .09, F(2,49) \quad 2.42, p \quad .10$.

\section{Evading discussion}

The total time spent evading discussion with opponents could be predicted significantly by the implicit affiliation motive, $t(51) \quad 2.36, p \quad .02$. The higher a player's implicit affiliation motive was, the more he accepted the referee's decisions and evaded dis cussion with his opponent, $\beta \quad$.32. The explicit affiliation motive in turn did not significantly predict the nonverbal behavior of evasion of discussion with the opponent, $t(51) \quad 0.82, \beta \quad .11, p \quad .42$. The overall regression model was significant and accounted for $11 \%$ of the variance in evading discussions, $R^{2} \quad .11, F(2,49) \quad 3.01, p \quad .05$.

\section{Supplemental analyses}

For potential reviews or meta analyses we additionally calcu lated correlation coefficients between the implicit and explicit motives of achievement and power and the measures of social behavior used in the present study. The implicit power motive was not significantly correlated with pleasant behavior at side change $\left(\begin{array}{lll}r & .06, p & .70\end{array}\right)$, evading discussion $\left(\begin{array}{lll}r & .15, p & .31\end{array}\right)$, overall verbal team contact $(r \quad .20, p \quad .17)$, or verbal team contact in breaks $\left(\begin{array}{lll}r & .22, p & .13\end{array}\right)$. Similarly, the explicit power motive was not significantly related with pleasant behavior at side change $(r \quad .17$, $p \quad .25)$, evading discussion ( $r \quad$.23, $p \quad .12)$, verbal team contact $\left(\begin{array}{lll}r & .03, p \quad .82\end{array}\right)$, or verbal team contact in breaks $\left(\begin{array}{lll}r & .07, p & .63\end{array}\right)$. The implicit achievement motive was neither correlated with pleasant behavior at side change $\left(\begin{array}{lll}r & .05, p & .73\end{array}\right)$, evading dis cussion $\left(\begin{array}{lll}r & .23, p & .12\end{array}\right)$, overall verbal team contact $\left(\begin{array}{ll}r & .10 \text {, }\end{array}\right.$ $p \quad .50)$ nor with verbal team contact in breaks $\left(\begin{array}{lll}r & .08, p & .58\end{array}\right)$. And finally, the explicit achievement motive was not significantly correlated with pleasant behavior at side change $\left(\begin{array}{lll}r & .08, p & .57\end{array}\right)$, evading discussion $(r \quad .25, p \quad .08)$, overall verbal team contact $\left(\begin{array}{lll}r & .06, p & .71\end{array}\right)$, or verbal team contact in breaks $(r \quad .18$, p .23).

\section{Discussion}

The aim of the present study was to find out whether the affiliation motive is able to predict social behavior expressed in high performance sports competition. This research was carried out in high performance situations and highlights the relevance of affiliation for real field settings. One of the main strengths of these results is that they can illustrate the discriminant validity of different motivational systems for real social behavior in a natural sports environment. The explicit affiliation motive was associated with verbal, controlled social behavior, such as verbal interaction with teammates. This finding is in line with research that linked explicit motives, which manifest themselves in direct questionnaire measures, with deliberate decisions and verbal, conscious infor mation processing (McClelland et al., 1989; Schultheiss, 2008). Moreover, social interaction with teammates is valued and ex pected in team competitions of racquet sports. It is assumed in these disciplines that athletes seek emotional and motivational support from coaches or teammates who might also help them with analyzing opponents. Regarding this, athletes in the present 
sample acted according to these expectations by spending more time talking to their coaches and teammates if they valued affilia tion (explicit motive). Higher explicit motive scores have also been found in team players compared to athletes in individual sports (Elbe et al., 2013; Teubel, 2012). Thus, results of this present study fit in with findings of stronger need for friendly relationships (Wong \& Csikszentmihalyi, 1991), higher self attributed coopera tiveness and sociability (Elbe et al., 2013), and more positive atti tudes and concern for teammates (Brewer \& Klein, 2006) found for individuals with a high explicit affiliation motive.

Nonverbal social behavior, in contrast, was associated with in direct measures of the implicit affiliation motive. The more an athlete is implicitly affiliation motivated the more accommodating he was toward his opponent. In the present study, this could be observed in social behavior pleasant to the opponent such as returning early to the court at side change or in the athlete's evading discussion with his opponent. This behavior was shown spontaneously and repeatedly over the course of the match, and it could be speculated that the athletes were not consciously aware of this behavior (McClelland, 1980; Schultheiss \& Pang, 2007). The present findings then are in line with studies that showed the implicit affiliation motive being associated with more accommo dating and pleasant behavior toward affiliative counterparts (Koestner \& McClelland, 1992; McClelland, 1975), as well as the tendency of implicitly affiliation motivated individuals to evade interpersonal conflicts with strangers and to live in peaceful envi ronments (Exline, 1962; Rokeach, 1973).

The present study was carried out in three individual interactive sports - tennis, table tennis, and badminton. Our main focus thereby was to differentiate between implicit affiliation behavior and explicit affiliation behavior, the latter of which we assumed would only occur because of the team setting in the league matches. Although athletes are used to competing on their own in singles competitions, the affiliation motive was linked to social interactions throughout the match in the present study. We assume that in a real team sports setting (e.g., basketball, soccer, volleyball) this link between the affiliation motives and social behavior might be even more pronounced. It could be expected that explicit and implicit motives may not be discriminated regarding different so cial behavior in these team sports, since athletes to a larger degree interact socially consciously as well as unconsciously. Social inter action is rather innate to the team sports of basketball or soccer, and explicitly valued at the same time.

\section{Indirect measures in the field of sports and exercise}

Information processing, such as in the implicit motive system, is characterized as affect based, associative, automatic, impulsive, and to a large degree unconscious (Smith \& DeCoster, 2000; Strack \& Deutsch, 2004). Especially in high performance sports, motor con trol has to be very quick and efficient. Many movements are auto mated and elude conscious control to a large degree. Questionnaires tend to rather assess a person's attitudes, values, goals, beliefs, and explicit motives. Spangler (1992) could show that motive question naires (explicit motives) and picture story exercises (implicit motives) are largely uncorrelated. Thus, if a researcher is interested in the prediction of unconscious, automated, spontaneously, and repeatedly shown behavior indirect measures need to be applied. Attempts have recently been made to illustrate the discriminant validity of indirect measures compared to questionnaires for the field of sports and ex ercise. For example, with a version of the Implicit Association Test (IAT; Greenwald, McGhee, \& Schwartz, 1998) it could be shown that physically active students responded faster to positive words associ ated with exercise than physically inactive students did (Bluemke, Brand, Schweizer, \& Kahlert, 2010). This illustrated that active students' spontaneous association with sports and exercise was more positive. Another study made use of the concept of implicit associa tions for aggressiveness (Teubel, Asendorpf, Banse, \& Schnabel, 2011). It could be shown there that only the indirect (but not the question naire) measure of aggressiveness was able to predict playing time in real competitions of basketball. In the present study, spontaneously and repeatedly shown, and presumably unconscious behavior toward the opponent could only be predicted by an indirect measure of the affiliation motive. All these findings are encouraging for a more frequent application of indirect measures in the field of sports and exercise when it comes to predicting automatic and spontaneous athletic behavior.

\section{Limitations, future directions, and practical implications}

The research results presented here are subject to some limi tations. First, two variables in the present study described nonverbal social behavior shown toward the opponent. Both, pleasant behavior toward the opponent at side change, and evasion of discussion, are assumed to occur without the athlete being aware of it. This is in line with theoretical assumptions that link implicit motives to non conscious, spontaneously shown behavior (McClelland et al., 1989). However, we did not directly ask the athletes how much they think they showed pleasant behavior toward their opponents. Future research could also assess whether an athlete is aware of his behavior toward the opponent. It could provide additional evidence for the uncon scious nature of such behavior if the athletes' self evaluation of their social behavior toward the opponent cannot be related to their observed behavior.

Additionally, participants in this study were from different na tions and speak different mother tongues. Although it is a strength of the present research to find association across individuals from different nations, one could argue that language barriers might have affected athletes' responses to the measures used in the present study. However, all of the players tested were professional athletes who were either tested in their mother tongue German or were very fluent in English because they use English to communicate with fellow athletes in different clubs or at international tournaments.

Also, the three sports observed differed with regard to the length of the individual matches. As such, it might affect athletes' levels of fatigue or concentration. The aim of the study was to point at findings that are generalizable to a class of sports (e.g., racquet sports). At least statistics of the present study show that athletes from the different sports did not vary with regard to the variables observed. Yet, the subsamples are rather small. Future studies might focus on one specific sport to have more standardized set tings or include larger samples in each sport.

The data presented here is composed of only a single match per athlete recorded during the same season for all athletes. This was primarily due to practical reasons regarding data collection and analysis. The process of analysis for the data presented here included several hours of behavior and motive coding for a single person. More matches might possibly have enhanced intra individual reliabilities. However, we assumed that errors made by selecting only one match per athlete (e.g., form on the day, referee) would not be subject to systematic error. Even though we only collected data from one match, we would like to stress that con cerning the measures of social behavior, this one match included behavioral data from $30 \mathrm{~min}$ up to two hours and several data points for each variable for every participant.

Additionally, for the variable 'evading discussion' we did not control for whether the referee's decision was actually controver sial. However, since the games were recorded in the highest German leagues with the best German referees we assumed that 
mistaken calls are randomly distributed throughout different sports and different matches.

For racquet sports practice, it is interesting to see that the affiliation motive is linked to athletes' social behavior. One question is whether the social behavior actually supports sports perfor mance or interferes with it. Future studies may focus on the content of verbal interaction, or how social behavior moderates the effect of motives on match performance. It could be assumed that functional verbal interaction like discussing match plans or asking teammates for help with emotion regulation may benefit performance. In contrast, non match related conversation may take time away from the athlete to individually work on match plans or regulate emotion and arousal. Furthermore, it could be examined whether friendly behavior toward the opponent actually affects game outcomes. As examined here, this behavior is supposed to be intuitive and not explicitly represented. In order to change such behavior, players would have to develop explicit strategies how to behave at side change or after breaks in order to produce optimal "friction" in the interaction with opponents and force them to make mistakes. However, the focus of the present research was only on analyzing the prevalence of affiliation motivated social behavior in highly competitive sports settings. How this may affect performance is the task of future studies.

Practical implications of the present findings are that even in a highly competitive sport situation individuals seek to satisfy the basic need for affiliation. Athletes, coaches, and sport psychologists alike need to be aware that athletes high in the affiliation motive will look for opportunities for social interaction during a match. Pointing athletes to potential social behavior thus may enhance their well being during competition. Especially for athletes high in the affiliation motive, competition often represents a downside of participation in sports. The varying social behaviors measured within the present research offer opportunities to render elite sports a more pleasant experience for affiliation motivated ath letes. In the present research, we only looked at singles competi tions. It could be assumed that athletes high in the affiliation motive avoid singles competitions and prefer doubles. Future research may look further at the affiliation motive of specialized doubles players compared to singles players.

Our findings also suggest that the explicit affiliation motive is rather satisfied by team contact, which was allowed in the team competitions observed. However, in tennis singles competitions in the ATP tour no team member is allowed on the bench and contact to coaches and teammates is penalized. For such competitions, coaches must carefully consider how athletes high in the explicit affiliation motive may interact socially during the game (e.g., with the referee). Beside such situational moderating variables (presence of a team member) variables of individual differences like extraversion may moderate how athletes' affiliation motive will affect social behavior on court (Winter, Stewart, John, Klohnen, \& Duncan, 1998).

Summarizing, the present research illustrates how even in highly competitive settings athletes in racquet sports use opportunities for social interaction depending on the strength of their explicit and implicit affiliation motives. For coaching staff and researchers alike it is important that athletes' on court behavior should not exclu sively be analyzed as to their motivation to win and achieve but also regarding athletes' tendency to satisfy their affiliative needs.

\section{Acknowledgment}

This work was supported by the Federal German Institute of Sport Science under Grant IIA1071006/0911. The funding source was neither involved in the process of collection, analysis, or interpretation of the data nor in the writing process of the report including the decision for submission of the manuscript.

\section{References}

Bluemke, M., Brand, R., Schweizer, G., \& Kahlert, D. (2010). Exercise might be good for me, but I don't feel good about it: do automatic associations predict exercise behavior? Journal of Sport \& Exercise Psychology, 32(2), 137153.

Brewer, S., \& Klein, J. D. (2006). Type of positive interdependence and affiliation motive in an asynchronous, collaborative learning environment. Educational Technology Research and Development, 54(4), 331 354. http://dx.doi.org/ 10.1007/s11423-006-9603-3.

Brown, D. T., O'Connor, J. P., \& Barkatsas, A. N. (2009). Instrumentation and motivation for organized cycling: the development of the Cyclist Motivation Instrument (CMI). Journal of Sports Science and Medicine, 8(2), 211218.

deCharms, R., Morrison, H. W., Reitman, W., \& McClelland, D. C. (1955). Behavioral correlates of directly and indirectly measured achievement motivation. In D. C. McClelland (Ed.), Studies in motivation (pp. 414 423). New York: AppletonCentury-Crofts.

Dixon, N. (2007). Trash talking, respect for opponents and good competition. Sport, Ethics and Philosophy, 1(1), 96 106. http://dx.doi.org/10.1080/17511320601143025.

Elbe, A.-M., Krippl, M., Melzer, M., \& Teubel, T. (2013). Testgütekriterien des Fragebogens AnMS-Sport zur Erfassung des Anschlussmotivs im Sportkontext [Development and analysis of the test control criteria of the AnMS-Sport questionnaire which assesses the sport-specific affiliation motive]. Sportwissenschaft. http://dx.doi.org/10.1007/s12662-012-0278-0.

Exline, R. V. (1962). Need affiliation and initial communication behavior in problem-solving groups characterized by low interpersonal visibility. Psychological Reports, 10(1), 7989.

Exline, R. V. (1963). Explorations in the process of person perception: visual interaction in relation to competition, sex, and need for affiliation. Journal of Personality, 31(1), 1 20. http://dx.doi.org/10.1111/j.1467-6494.1963.tb01836.x.

French, E. G., \& Chadwick, I. (1956). Some characteristics in affiliation motivation. Journal of Abnormal and Social Psychology, 52(3), 296 300. http://dx.doi.org/ 10.1037/h0045251.

Gill, D. L. \& Williams, L. (1996). Competitive orientations and motives of adult sport and exercise participants. Journal of Sport Behavior, 19(4), 307.

Greenwald, A. G., McGhee, D. E., \& Schwartz, J. L. K. (1998). Measuring individual differences in implicit cognition: the implicit association test. Journal of Personality and Social Psychology, 74(6), 1464 1480. http://dx.doi.org/10.1037/ 0022-3514.74.6.1464.

Jackson, D. N. (1999). Personality research form manual (3rd ed.). New York: Research Psychologists Press.

Jemmott, J. B. (1987). Social motives and susceptibility to disease: stalking individual differences in health risks. Journal of Personality, 55(2), 267 298. http:// dx.doi.org/10.1111/j.1467-6494.1987.tb00437.x.

Koestner, R., \& McClelland, D. C. (1992). The affiliation motive. In C. P. Smith (Ed.), Motivation and personality: Handbook of thematic content analysis (pp. 205 210). New York: Cambridge University Press.

Kuhl, J., \& Kazén, M. (2008). Motivation, affect, and hemispheric asymmetry: power versus affiliation. Journal of Personality and Social Psychology, 95(2), 456469. http://dx.doi.org/10.1037/0022-3514.95.2.456.

Kuhl, J., \& Scheffer, D. (1999). Der Operante Multi-Motiv-test (OMT): Manual [The Operant Multimotive Test (OMT): Manual]. Osnabrück, Germany: University of Osnabrück.

Lansing, J. B., \& Heyns, R. W. (1959). Need affiliation and frequency of four types of communication. Journal of Abnormal and Social Psychology, 58(3), 365372 http://dx.doi.org/10.1037/h0045906.

McAdams, D. P., \& Constantian, C. A. (1983). Intimacy and affiliation motives in daily living: an experience sampling analysis. Journal of Personality and Social Psychology, 45(4), 851 861. http://dx.doi.org/10.1037/0022-3514.45.4.851.

McAdams, D. P., Healey, S., \& Krause, S. (1984). Social motives and patterns of friendship. The Journal of Personality and Social Psychology, 47(4), 828838. http://dx.doi.org/10.1037/0022-3514.47.4.828.

McClelland, D. C. (1975). Power: The inner experience. New York: Irvington Publishers.

McClelland, D. C. (1980). Motive dispositions: the merits of operant and respondent measures. In L. Wheeler (Ed.), Review of personality and social psychology (Vol. 1); (pp. 10 41). Beverly Hills: Sage.

McClelland, D. C. (1985a). How motives, skills, and values determine what people do. American Psychologist, 40(7), 812 825. http://dx.doi.org/10.1037/0003066X.40.7.812.

McClelland, D. C. (1985b). Human motivation. Glenview: Scott, Foresman \& Co.

McClelland, D. C., Koestner, R., \& Weinberger, J. (1989). How do self-attributed and implicit motives differ? Psychological Review, 96(4), 690 702. http://dx.doi.org/ 10.1037/0033-295X.96.4.690.

Mehrabian, A. (1970). The development and validation of measures of affiliative tendency and sensitivity to rejection. Educational and Psychological Measurement, 30, 417 428. http://dx.doi.org/10.1177/001316447003000226.

Rokeach, M. (1973). The nature of human values. New York: Free Press.

Scheffer, D. (2001). Entwicklungsbedingungen impliziter Motive: Bindung, Leistung \& Macht [Developmental conditions of implicit motives: Affiliation, Achievement, \& Power] (Doctoral thesis). Germany: Universitat Osnabrück.

Scheffer, D., Eichstaedt, J., Chasiotis, A., \& Kuhl, J. (2007). Towards an integrated measure of need affiliation and agreeableness derived from the operant motive test. Psychology Science, 49(4), 308324. 
Scheffer, D., Kuhl, J., \& Eichstaedt, J. (2003). Der Operante Motiv-Test (OMT): Inhaltsklassen, Auswertung, psychometrische Kennwerte und Validierung [The Operant Motive Test (OMT): contents, scoring, psychometric values, and validation]. In J. Stiensmeier-Pelster, \& F. Rheinberg (Eds.), Diagnostik von Motivation und Selbstkonzept [Diagnostic of motivation and self-concept]. Gottingen, Germany: Hogrefe.

Schüler, J., Job, V., Frohlich, S. M., \& Brandstatter, V. (2008). A high implicit affiliation motive does not always make you happy: a corresponding explicit motive and corresponding behavior are further needed. Motivation and Emotion, 32(3), 231 242. http://dx.doi.org/10.1007/s11031-008-9096-y.

Schultheiss, O. C. (2008). Implicit motives. In O. P. John, R. W. Robins, \& L. A. Pervin (Eds.), Handbook of personality: Theory and research (3rd ed.) (pp. 603 633). New York: Guilford Press.

Schultheiss, O. C., \& Pang, J. S. (2007). Measuring implicit motives. In R. W. Robins, R. C. Fraley, \& R. Krueger (Eds.), Handbook of research methods in personality psychology (pp. 322 344). New York: Guilford.

Sève, C., Ria, L., Poizat, G., Saury, J., \& Durand, M. (2007). Performance-induced emotions experienced during high-stakes table tennis matches. Psychology of Sport and Exercise, 8, 25 46. http://dx.doi.org/10.1016/j.psychsport.2006.01.004.

Sève, C., Saury, J., Theureau, J., \& Durand, M. (2002). Activity organization and knowledge construction during competitive interaction in table tennis. Cognitive Systems Research, 3, 501522.

Shields, D. L., Bredemeier, B. L., LaVoi, N. M., \& Power, F. C. (2005). The sport behavior of youth, parents, and coaches: the good, the bad, and the ugly. Journal of Research in Character Education, 3(1), 4359.

Smith, E. R., \& DeCoster, J. (2000). Dual-Process models in social and cognitive psychology: conceptual integration and links to underlying memory systems. Personality and Social Psychology Review, 4(2), 108 131. http://dx.doi.org/ 10.1207/S15327957PSPR0402_01.

Sokolowski, K. (2008). Social bonding: affiliation motivation and intimacy motivation. In J. Heckhausen, \& H. Heckhausen (Eds.), Motivation and action (pp. 184 201). Cambridge: Cambridge University Press.

Sorrentino, R. M., \& Field, N. (1986). Emergent leadership over time: the functional value of positive motivation. Journal of Personality and Social Psychology, 50(6), 1091 1099. http://dx.doi.org/10.1037/0022-3514.50.6.1091.
Sorrentino, R. M., \& Sheppard, B. H. (1978). Effects of affiliation-related motives on swimmers in individual versus group competition: a field experiment. Journal of Personality and Social Psychology, 36(7), 704714.

Spangler, W. D. (1992). Validity of questionnaire and TAT measures of need for achievement: two meta-analyses. Psychological Bulletin, 112(1), 140 154. http:// dx.doi.org/10.1037/0033-2909.112.1.140.

Strack, F., \& Deutsch, R. (2004). Reflective and impulsive determinants of social behavior. Personality and Social Psychology Review, 8(3), 220 247. http:/l dx.doi.org/10.1207/s15327957pspr0803_1.

Stumpf, H., Angleitner, A., Wieck, T., Jackson, D. N., \& Beloch-Till, H. (1985). Deutsche Personality Research Form (PRF) [German Personality Research Form]. Gottingen: Hogrefe.

Sudeck, G., Lehnert, K., \& Conzelmann, A. (2011). Motivbasierte Sporttypen: auf dem Weg zur Personenorientierung im zielgruppenspezifischen Freizeit- und Gesundheitssport [Motive-based types of sports person: Towards a personoriented approach in target group-specific leisure and health sports]. Zeitschrift für Sportpsychologie, 18(1), 117.

Teubel, T. (2012). Das Anschlussmotiv zur Erklarung sportlicher Leistungen [The affiliation motive as a predictor for sports performance]. Hamburg: Verlag Dr. Kovac.

Teubel, T., Asendorpf, J. B., Banse, R., \& Schnabel, K. (2011). Implicit but not explicit aggressiveness predicts performance outcome in basketball players. International Journal of Sport Psychology, 42, 390400.

Wegner, M., Schüler, J., \& Budde, H. (2014). The implicit affiliation motive moderates cortisol responses to acute psychosocial stress in high school students. Psychoneuroendocrinology. http://dx.doi.org/10.1016/j.psyneuen.2014.06.013.

Wegner, M., \& Teubel, T. (2014). The implicit achievement motive predicts match performances and the explicit motive predicts choices for goal distances in team sports. International Journal of Sport Psychology (in press).

Wong, M. M., \& Csikszentmihalyi, M. (1991). Affiliation motivation and daily experience: some issues on gender differences. Journal of Personality and Social Psychology, 60(1), 154 164. http://dx.doi.org/10.1037/0022-3514.60.1.154.

Winter, D. G., Stewart, A., John, O. P., Klohnen, E. C., \& Duncan, L. E. (1998). Traits and motives: toward an integration of two traditions in personality research. Psychological Review, 105(2), $230250 . \quad$ http://dx.doi.org/10.1037/0033295X.105.2.230. 